\title{
MOVIMENTOS DE VERTENTE NO NORTE DE PORTUGAL: IMPORTÂNCIA DO COMPORTAMENTO HIDROLÓGICO DAS FORMAÇÕES SUPERFICIAIS
}

\section{SLOPE MOVEMENTS IN NORTHERN PORTUGAL: IMPORTANCE OF SURFICIAL FORMATIONS HYDROLOGICAL BEHAVIOR}

Carlos Valdir de Meneses Bateira

Departamento de Geografia, Universidade do Porto

Via Panorâmica, s/n, 4150-564 Porto, Portugal E-mail: carlosbateira@gmail.com

\section{Laura Maria Pinheiro Machado Soares}

Departamento de Geografia, Universidade do Porto

Via Panorâmica, s/n, 4150-564 Porto, Portugal

E-mail: Impsoares@gmail.com

\section{Diogo Manuel Moreira Rodrigues}

Departamento de Geociências, Ambiente e Ordenamento do Território, Universidade do Porto Rua Campo Alegre 687, 4169-007 Porto, Portugal E-mail:dmmrodrigues@gmail.com

Rui Miguel Marques Moura Departamento de Geociências, Ambiente e Ordenamento do Território, Universidade do Porto Rua Campo Alegre 687, 4169-007 Porto, Portugal

E-mail: rmmoura@fc.up.pt

Manuel António da Cunha Teixeira

Departamento de Geografia, Universidade do Porto

Via Panorâmica, s/n, 4150-564 Porto, Portugal E-mail: mane.teixeira@gmail.com

Mónica Sofia Moreira Santos

Centro de Estudos Geográficos, Universidade de Lisboa Alameda da Universidade, 1600-214 Lisboa, Portugal E-mail:monica.s.m.santos@gmail.com

Informações sobre o Artigo

Data de Recebimento:

30/04/2014

Data de Aprovação:

08/07/2014

\section{Resumo:}

A ocorrência de movimentos de vertente no Norte de Portugal tem motivado o desenvolvimento de vários estudos de caso, ensaiando-se diversas metodologias que visam definir e caracterizar os factores condicionantes que maior influência exercem sobre os processos de instabilidade. Neste trabalho apresentam-se 


\section{Palavras-chave:}

Movimentos de vertente;

Formações superficiais;

Hidrologia de vertentes; Norte de Portugal.

\section{Keywords:}

Landslides; Surficial

formations; Slope hydrology;

Northern Portugal. os resultados obtidos para o fluxo de detritos de Frades (Arcos de Valdevez), discutindo-se a importância do contexto morfo-estrutural, das formações superficiais e do seu comportamento hidrológico, analisados através de ensaios laboratoriais e in situ, designadamente, granulometria, composição mineralógica, condutividade hidráulica, resistência à penetração e refracção sísmica. O estudo desenvolvido, para além de demonstrar a existência de caminhos preferenciais da circulação interna da água, em associação com condicionamentos ligados às características das formações superficiais, revela que a rede de drenagem subsuperficial tem uma ligação evidente com o escoamento que se processa à superfície, embora possa sofrer alterações motivadas por estruturas subjacentes.

\begin{abstract}
:
The occurrence of landslides in northern Portugal has motivated the development of several case studies, rehearsing different methodologies that seek to define and characterize the conditioning factors with the greatest influence over the geomorphologic instability processes. This paper presents the results obtained for Frades (Arcos de Valdevez) debris flow, discussing the importance of morphostructural context, surficial formations and their hydrological behavior, analyzed by in situ and laboratory tests, namely, grain size, mineralogy, hydraulic conductivity, penetration resistance and seismic refraction. The developed study shows the existence of preferential paths of internal water circulation, in combination with constraints linked to the characteristics of the surficial formations, revealing also that the subsurface drainage network has an obvious link with the flow that takes place at the surface, although it may present changes motivated by underlying structures.
\end{abstract}

\section{Introdução}

Embora em Portugal os movimentos de vertente não apresentem a magnitude, frequência e o cariz devastador que evidenciam noutros países, estudos desenvolvidos demonstram a sua relevância no âmbito dos riscos naturais que afectam o território nacional (Zêzere et al., 2007). Este panorama é reflectido pela base de dados Disaster - um inventário elaborado em SIG que compila os processos hidrogeomorfológicos que implicaram danos pessoais em Portugal Continental - salientandose que entre 1865 e 2010 ocorreram um total de 281 movimentos de vertente, dos quais resultaram 239 mortos, 422 feridos, 23 desaparecidos e 2380 desalojados/ evacuados (Bateira et al., 2013). Este cenário justifica a inserção destes processos de instabilidade geomorfológica no âmbito do Planeamento, Ordenamento do Território e Protecção Civil (Zêzere et al., 2004; Zêzere, 2007; Pereira et al., 2007; Bateira, 2010), assim como a publicação de normas, princípios e metodologias a que deve obedecer a cartografia de susceptibilidade (Julião et al, 2009), o que tem motivado a aplicação de modelos de base física e estatística a diferentes áreas do país (Zêzere, 2001; Pereira, 2009; Oliveira et al. 2010; Pimenta, 2011; Vasconcelos, 2011; Teixeira, 2012; Teixeira et al., 2013; Teixeira et al., 2014).
Centrando-nos no cenário que a BD Disaster reflecte para os movimentos registados no norte de Portugal nos 145 anos em análise, verifica-se um total de 110 ocorrências em que assumem maior destaque os desabamentos de terra e rocha $(37 \%$ e $33 \%$, respectivamente) e os fluxos de detritos (14,5\%), reafirmando as tipologias já indicadas em estudos prévios como mais frequentes em áreas do Maciço Antigo (Bateira, 2001; Soares, 2008). Estes processos implicaram 131 mortos, 188 feridos, 22 desaparecidos (MFD) e 724 evacuados e desalojados (ED) (Figura 1).

Se a precipitação, designadamente a sua intensidade e duração, se assume como o principal fator desencadeante dos movimentos de vertente em Portugal (Bateira e Soares, 1997; Santos e Fragoso, 2010), estes processos são condicionados por um conjunto de outras variáveis intimamente relacionadas, em que se destacam a textura e espessura das formações superficiais (pela influência que exercem sobre a capacidade de infiltração, circulação e armazenamento de água) e a estrutura geológica, designadamente a litologia e a tectónica, esta última refletindo-se sobre a fracturação dos materiais e, assim, facilitando a sua rutura e meteorização. Outros fatores, como o declive, área de contribuição, ângulo de atrito, o tipo e densidade do coberto vegetal e o uso do 


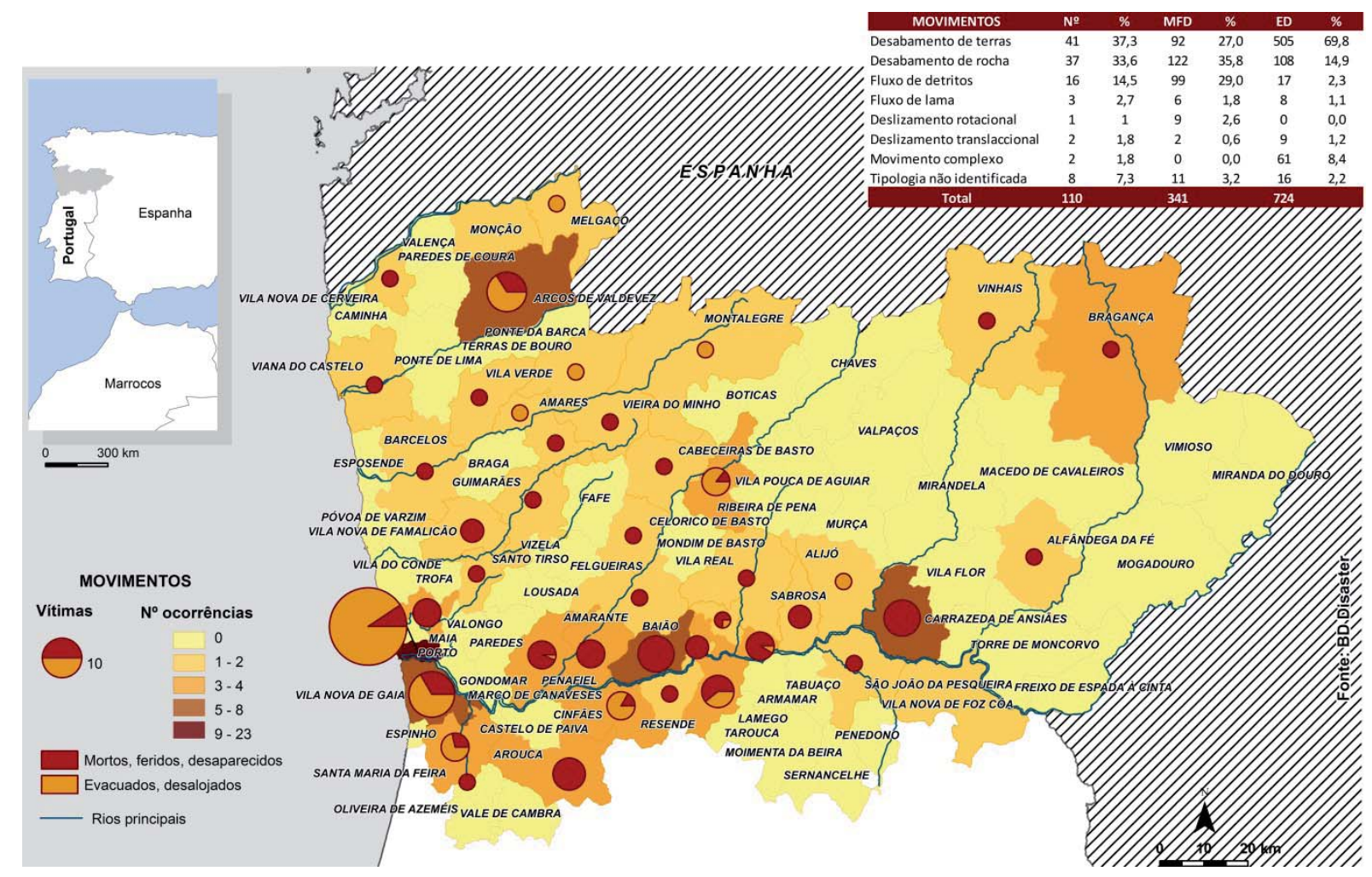

Figura 1 - Movimentos de vertente no norte de Portugal: número de ocorrências e danos implicados, por concelho.

solo constituem parâmetros adicionais, cujo efeito deve ser avaliado em função das características da área em estudo, nomeadamente ao nível da intervenção antrópica (Soares et al., 2007).

\section{Objectivos, Enquadramento Espacial e Metodo- logias}

Este estudo tem como objetivo principal demonstrar a influência que o comportamento hidrológico das formações superficiais exerce sobre a ocorrência de movimentos de vertente no norte de Portugal. Para o efeito, apresentam-se e discutem-se as metodologias e resultados obtidos na caracterização do fluxo de detritos que ocorreu a 7 de Dezembro de 2000 e que motivou a morte de 4 pessoas e prejuízos económicos consideráveis em Frades (Arcos de Valdevez), um pequeno núcleo rural localizado no noroeste de Portugal (Figura 2).

O processo desenvolveu-se numa vertente côncava cujo declive médio ronda os $30^{\circ}$, apresentando um coberto pouco denso e disperso de vegetação herbácea e arbustiva, suportado por um manto de alteração incipiente por vezes subjacente a um depósito de vertente heterométrico pouco espesso e de matriz argilosa abundante. $\mathrm{O}$ substrato rochoso da secção superior da vertente é constituído por um granito de grão médio a fino (Granito do Extremo) que, embora pouco alterado, evidencia uma densa fracturação associada à existência de uma falha quase vertical de direção aproximada $\mathrm{N} 20^{\circ} \mathrm{E}$, que corta transversalmente o arco definido pela cicatriz principal do fluxo. Este acidente estabelece a transição para o granito de grão grosseiro a médio da Serra Amarela, através de uma caixa de falha com cerca de 4,7m de largura, onde o material se encontra extremamente argilizado. Na margem esquerda da cicatriz observa-se ainda um filão aplito-pegmatítico, que atravessa perpendicularmente a falha referida segundo uma orientação EESE-WNW (Soares, 2008). Embora os materiais transportados pelo fluxo tenham percorrido, no total, uma distância de cerca de $800 \mathrm{~m}$, entre a área da cicatriz e o sector onde se acumularam os detritos de maior dimensão define-se um percurso que ronda os $380 \mathrm{~m}$, vencendo um desnível aproximado de $180 \mathrm{~m}$.

A metodologia utilizada no estudo do movimento, envolveu um conjunto de ensaios laboratoriais e in situ, visando sobretudo caracterizar o comportamento hidrológico das formações superficiais da área, considerando a sua textura, composição mineralógica, espessura, resistência à penetração e condutividade hidráulica. 

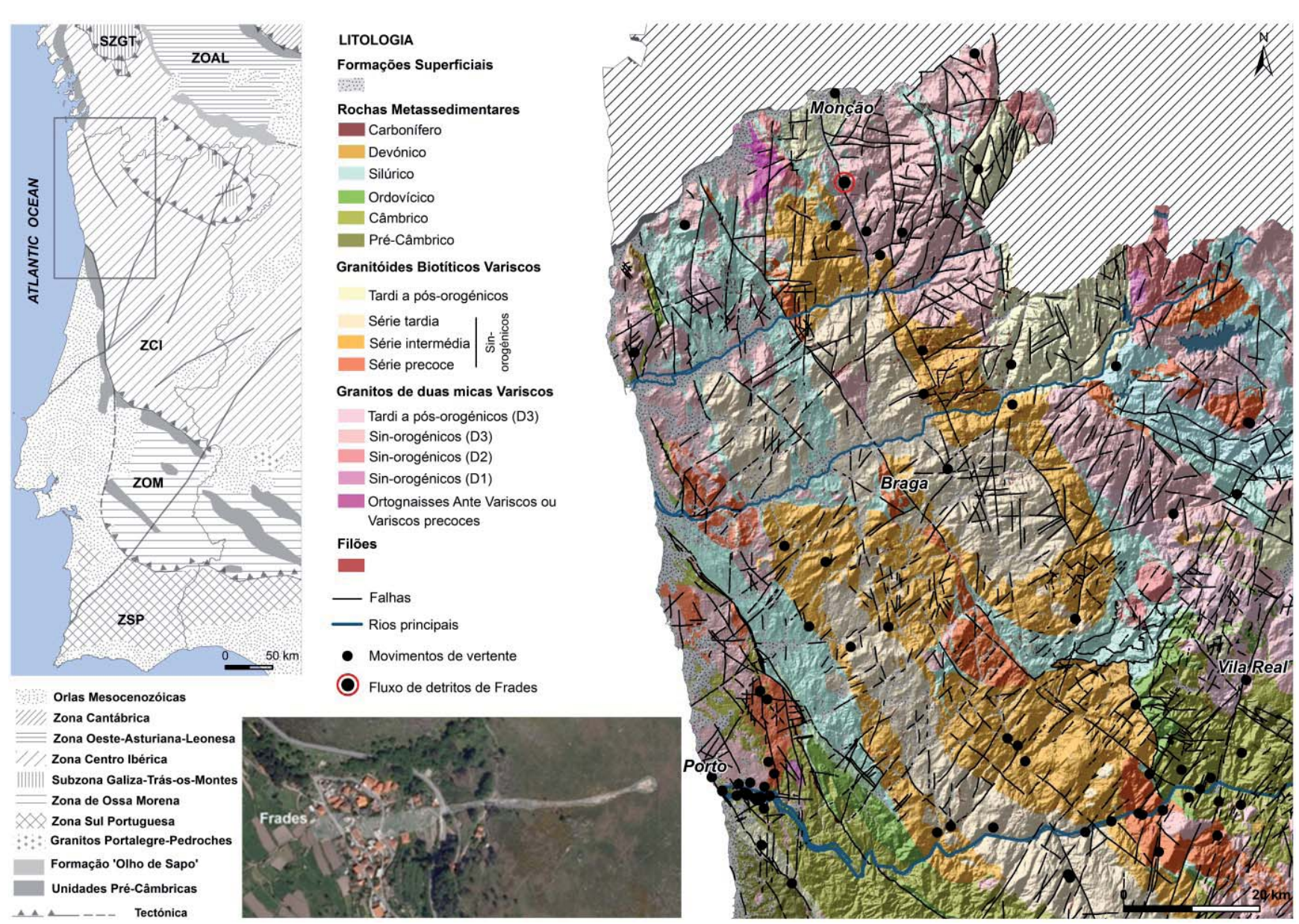

Figura 2 - Localização e enquadramento estrutural do fluxo de detritos de Frades.

Para avaliar os aspetos texturais, foram recolhidas várias amostras na proximidade da cicatriz, abrangendo os distintos tipos de materiais: manto de alteração, depósito de vertente, faixa de transição/esmagamento que estabelece o contacto entre os dois granitóides que afloram na área e material argilizado de preenchimento da falha. Procedeu-se ainda à análise da composição mineralógica da fração inferior a $2 \mu \mathrm{m}$ (por difração de raios $\mathrm{x}$ ), pretendendo-se sobretudo identificar o tipo de argilas presentes.

A resistência à penetração foi avaliada através de um penetrómetro de cone estático (Hand Penetrometer, modelo da Eijkelkamp), que nos permite inferir a coesão, compacidade e espessura dos materiais, explorando, precisamente, as variações de resistência entre diferentes níveis das formações superficiais (Sanglerat, 1972; Murthy, 2002). Os ensaios foram realizados em torno da cicatriz de 'arranque', considerando-se três segmentos espaçados de $2 \mathrm{~m}$ e englobando 42 pontos de leitura até um máximo de $1 \mathrm{~m}$ de profundidade, registando-se os valores em intervalos de $5 \mathrm{~cm}$.

A condutividade hidráulica foi determinada através do Permeâmetro de Guelph, cujos resultados nos permitem calcular: a Saturação da Condutividade Hidráulica, que corresponde à (...) velocidade média constante percorrida pela água por unidade de tempo numa determinada seç̧ão do solo, por troca com o ar existente entre as suas partículas (Soares, 2008, p.221); a Matriz do Fluxo Potencial, um indicador da capacidade que o solo tem para absorver água, por ação da capilaridade; e o Parâmetro Alfa, cujo cálculo combina os resultados dos dois índices anteriores - relacionandose com a porosidade do solo - sabendo-se que quanto mais elevado for o seu resultado maior será a velocidade de circulação da água no interior do solo (Reynolds, 1993; Silvério, 2000; Soares et al., 2010).

$\mathrm{Na}$ refração sísmica, utilizada com o objetivo de obter dados mais concretos sobre a espessura das 
formações superficiais e para determinar os caminhos preferenciais de escoamento subsuperficial, foi usado o sismógrafo Geometrics StrataVisor NZ com 24 geofones, aplicado em 4 transeptos: um longitudinal e paralelo ao corpo principal do fluxo de detritos; os outros três foram definidos cortando transversalmente a parte superior, média e inferior do canal de transporte talhado pelo movimento (Pinho, 2003; Rodrigues, 2013). A informação resultante foi posteriormente tratada com o software Ras-24, enquanto os valores de espessura foram calculados através do RockWorks15.

Com o objetivo de avaliar o padrão espacial de saturação do solo, importante nos estudos de previsão de áreas de instabilidade geomorfológica, procedeu-se ainda ao cálculo da área de contribuição utilizando o método multi-direcional ou de transferência de fluxo distribuída (multiple flow direction) definido por Quinn et al. (1991), considerado o mais adequado e fiável para secções côncavas do relevo (Ramos et al., 2003; Guimarães et al., 2009).

\section{Apresentação e Discussão de Resultados}

\subsection{Influência da precipitação}

O factor desencadeante do fluxo de detritos de Frades encontra-se obviamente relacionado com a quantidade e intensidade da precipitação diária, que atingiu $170 \mathrm{~mm}$ - o segundo valor máximo anual diário da série de 41 anos da estação meteorológica de Extremo (situada a cerca de $1,5 \mathrm{~km}$ a NNW de Frades, a $419 \mathrm{~m}$ de altitude) - concentrados entre as $09.00 \mathrm{~h}$ e as $14.30 \mathrm{~h}$ do dia da ocorrência. No entanto, é importante referir que desde 30 de Outubro e até à data do movimento se observou uma sequência quase ininterrupta de precipitação, totalizando $1171.6 \mathrm{~mm}$ em 38 dias. Neste contexto, destaca-se sobretudo o período chuvoso que teve início a 20 de Novembro e que enquadra o fluxo, totalizando $928.2 \mathrm{~mm}$ em 17 dias (Figura 3). Como refere Soares (2008, p.457), este panorama (...) teve uma influência fulcral no desencadear do movimento de Frades, pelo que o seu desencadeamento na sequência da intensa chuvada do dia 7 de Dezembro, correspondeu, provavelmente, à 'gota de água' que despoletou a rutura das formações superficiais.

Comparativamente com outros estudos de movimentos ocorridos no norte de Portugal (i.e. Cavez, Covelo do Gerês, Cestães, Sta. Marinha do Zêzere,
Sta. Marta de Penaguião), o de Frades acentua uma tendência que associa episódios de precipitação com características distintas - ao nível da quantidade, intensidade e duração - ao tipo de processos de instabilidade. Efetivamente, verifica-se que os fluxos de detritos e de lama tendem a ocorrer em dias de precipitação máxima (embora enquadrados numa sequência chuvosa), enquanto os deslizamentos profundos, simples ou associados a outros processos (movimentos complexos), têm geralmente lugar após um período de chuva mais ou menos prolongado, mas sem que coincidam com os dias de maior precipitação (Soares e Bateira, 2013). No entanto, a importância das precipitações antecedentes é comum às tipologias analisadas, verificando-se igualmente uma relação importante com os meses em que ocorreram quantitativos bastante superiores à média.

Esta relação entre a tipologia dos movimentos e as características da precipitação é assinalada por vários autores (i.e. Wieczorek, 1996; Schuster e Wieczorek, 2002; Zêzere, et al., 2005), assim como se assiste a uma cada vez maior preocupação em definir limiares críticos de precipitação para a ocorrência de processos de instabilidade (i.e. Corominas e Moya, 1999; Crosta e Frattini, 2001; Guzzetti et al., 2007, 2008; Zêzere et al., 2008). Para o sul do território português, designadamente na região de Lisboa, a disponibilidade de dados permitiu já definir um panorama efectivo, considerando-se que a ocorrência de movimentos está relacionada com eventos de precipitação intensa e de curta duração (entre 1 e 15 dias) no caso de deslizamentos superficiais translativos, enquanto processos mais profundos e de maior dimensão se associam a episódios de longa duração, que variam entre 1 a 3 meses (Zêzere et al., 2005). Salienta-se ainda, para a mesma área, que grande parte das ocorrências de instabilidade implicavam uma precipitação antecedente de 30 dias superior a $80 \mathrm{~mm}$, em simultâneo com valores de precipitação diária que ultrapassavam os 24mm (Zêzere e Rodrigues, 2002).

Para o norte de Portugal, têm sido desenvolvidos alguns estudos neste domínio (Pereira, 2009; Pereira, Zêzere e Bateira, 2010), se bem que aplicados apenas aos fluxos de detritos e de lama, salientando-se que estes normalmente ocorrem em meses com precipitação bastante superior à média mensal, verificando-se ainda que (...) a precipitação antecedente de 10 dias combinada com a precipitação do evento de 3 dias é muito importante para o desenvolvimento destes processos, associada, obviamente, à precipitação do 


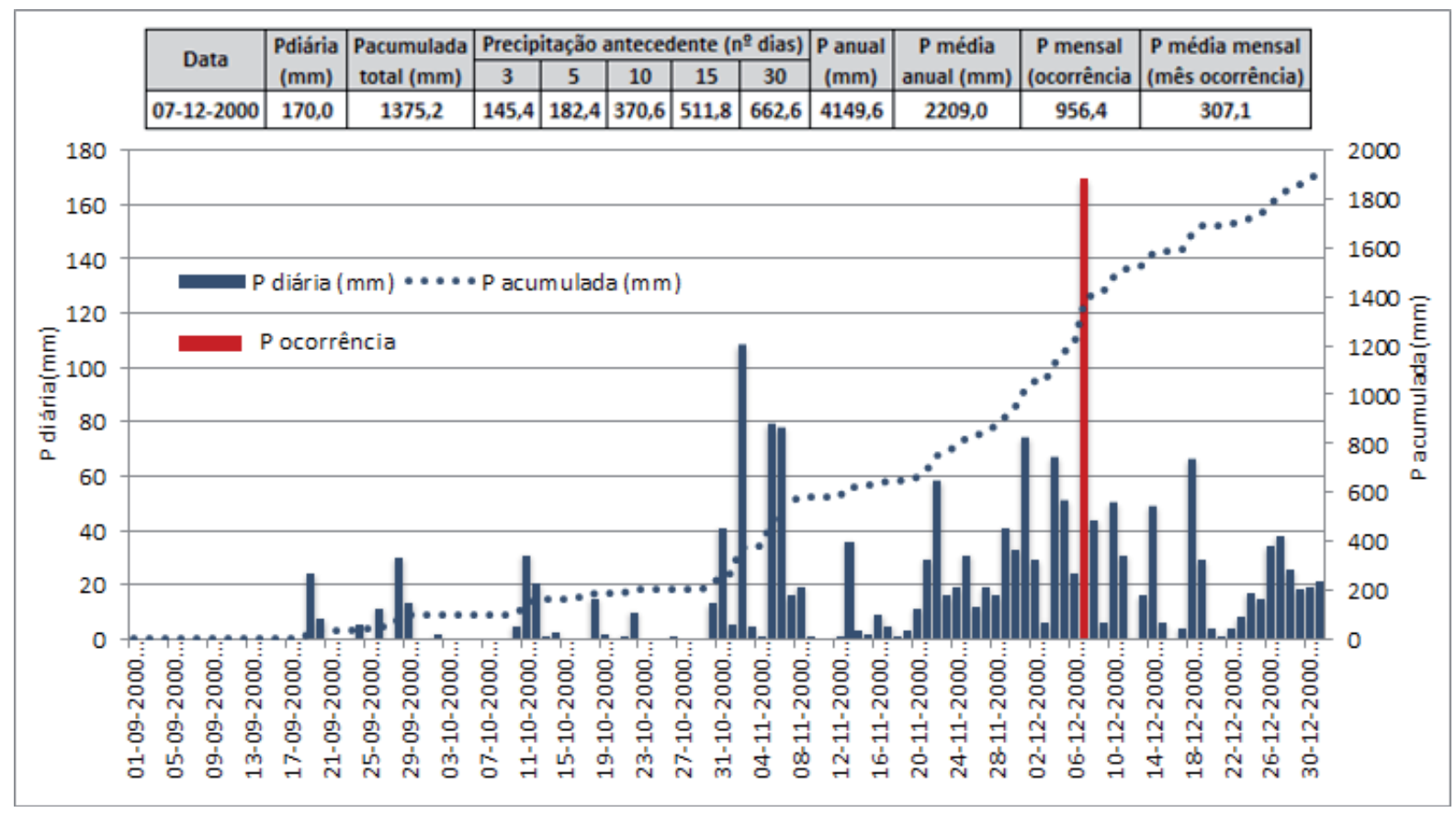

Figura 3 - Dados de precipitação associados ao movimento de Frades. Fonte: Estação meteorológica de Extremo.

evento (Pereira, ob.cit., p.197). O caso de Frades cumpre efetivamente estes requisitos - o mesmo se verificando em movimentos anteriormente estudados do mesmo tipo (i.e. Rio Frio, Sta. Marinha do Zêzere) - salientando-se, nomeadamente, que a precipitação do mês da ocorrência é três vezes superior à média mensal (cf. Figura 3), sendo esta também ultrapassada pelos valores da precipitação dos 10 dias antecedentes e realçando-se os $170 \mathrm{~mm}$ que caíram na data do fluxo.

Independentemente da aplicação prática que a definição de limiares críticos de precipitação possa ter, principalmente no âmbito da Proteção Civil, é preciso não esquecer que estes limiares são fortemente dependentes do contexto morfoclimático específico em que ocorrem os movimentos. Esta observação torna-se particularmente pertinente em áreas de fortes contrastes topográficos - como é o norte de Portugal - o que implica a existência de uma boa cobertura de estações meteorológicas que possam dar conta das variações topoclimáticas existentes, que, consequentemente, vão implicar a existência de limiares distintos consoante as áreas. Para além disso, a influência exercida por outros fatores condicionantes dos processos de instabilidade, designadamente as formações superficiais, introduz 'ruído' nesta avaliação. Com efeito, o comportamento hidrológico destes materiais depende da forma como as suas características intrínsecas - principalmente a espessura e textura - respondem aos episódios de precipitação (Soares e Bateira, 2010).

\subsection{Textura e mineralogia}

A granulometria das amostras recolhidas na área abrangida pela cicatriz do fluxo de Frades, revelam o predomínio da fração arenosa (Figura 4), variando entre a areia grosseira a muito fina, com médias que se situam entre $1 \mathrm{~mm}$ e $63 \mu \mathrm{m}$. No entanto, o teor de silte e argila assume valores importantes em alguns casos, principalmente na formação associada à falha (A3), onde atinge uma percentagem de quase $50 \%$. A percentagem de material grosseiro (superior a $2 \mathrm{~mm}$ ) é substancialmente mais baixa, só assumindo representatividade nos depósitos de vertente e no manto de alteração grosseiro. Comparativamente com os dados recolhidos de formações superficiais associadas a outros movimentos, podemos considerar que a textura dos materiais associados ao fluxo de Frades é bastante mais fina.

Relativamente à composição mineralógica da fracção inferior a $2 \mu \mathrm{m}$, destaca-se sobretudo a caulinite e a ilite pela regularidade da sua presença, por vezes em associação com gibsite, minerais argilosos que são frequentes em formações superficiais derivadas de rochas granitóides do Maciço Antigo do norte de Portugal (Furtado, 1981-82; Braga, 1988; Soares, 1992; Alves, 1995). 
No entanto, destaca-se a presença de montmorilonite na amostra coletada na área afetada pela falha (ArgF), provavelmente associada com condições específicas de drenagem: se a falha atua como sector privilegiado de circulação da água, o facto de se encontrar preenchida por quase $50 \%$ de silte e argila permite a concentração e retenção dos fluídos, o que favorece a génese desta argila expansiva que assume um importante papel na instabilidade de vertentes (Prior et al., 1971; Oyagi, 1984; Sharma et al., 2013).

Demonstrando a interdependência entre as características das formações superficiais e os episódios chuvosos no contexto dos processos de instabilidade, estudos desenvolvidos previamente referem que pela influência que exercem sobre a capacidade de infiltração, circulação e armazenamento de água, a textura combinada com a espessura dos materiais pode determinar o tipo de movimento que ocorre com mais frequência numa determinada área: formações texturalmente finas e peliculares tendem a originar essencialmente movimentos superficiais, como é o caso dos fluxos, em ligação com episódios chuvosos de forte intensidade e refletindo uma certa tendência para ocorrerem em dias de máxima pluviosidade, o que proporciona quantitativos de água que rapidamente ultrapassam o limiar de saturação dos materiais; em áreas onde dominam formações grosseiras e espessas há maior probabilidade de se desenvolverem movimentos profundos e por vezes faseados, designadamente deslizamentos que podem ou não evoluir para outro tipo de processos (movimentos complexos), geralmente associados a eventos chuvosos abundantes e prolongados (Innes, 1983; Wieczorek, 1996; Lambe, 1996; Brooks et al., 2002; Malet et al., 2003; Yalcin, 2007; Soares e Bateira, 2010, 2013).

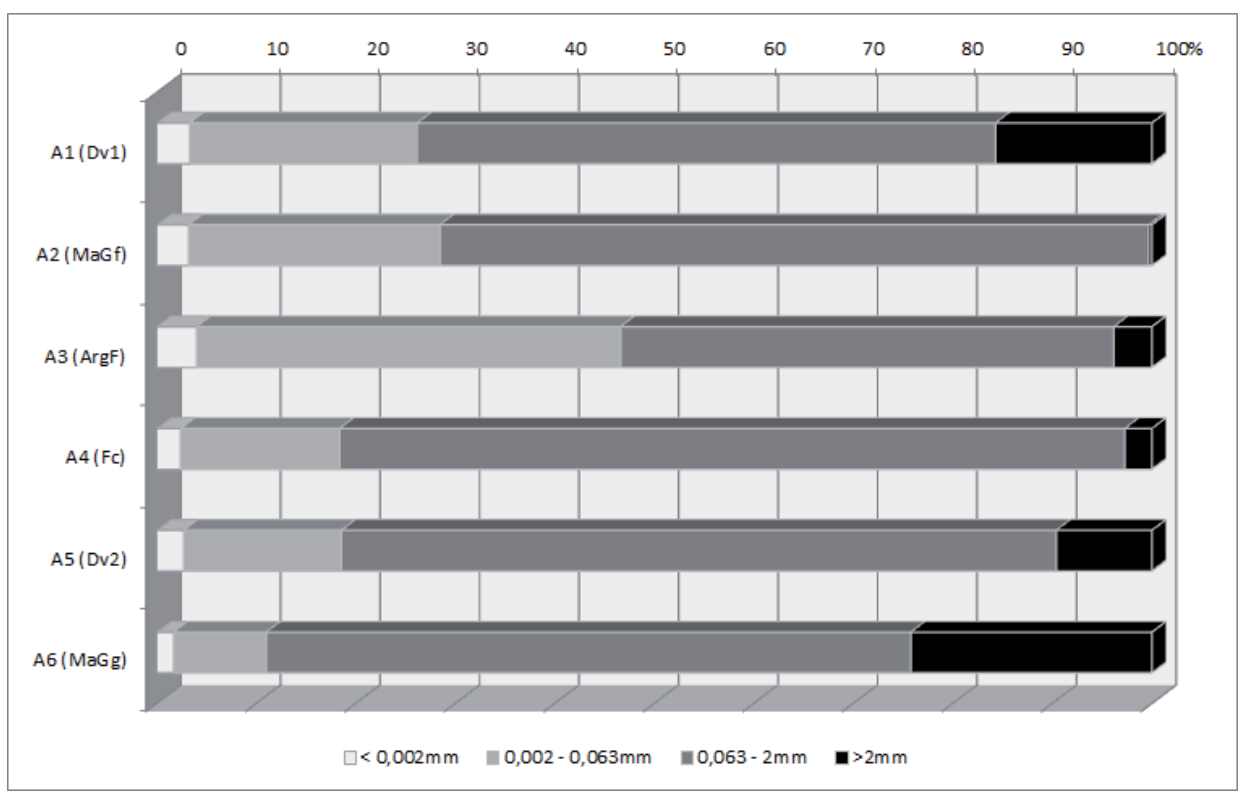

Figura 4 - Composição granulométrica das formações superficiais da área da cicatriz de Frades. Dv1 e 2 - depósitos de vertente; MaGf - Manto de alteração derivado do granito de grão médio a fino; MaGg - Manto de alteração associado ao granito de grão grosseiro a médio; ArgF - material de preenchimento da falha; Fc - material da faixa de contacto entre os granitóides.

Como exemplos dos primeiros poderíamos salientar, para além de Frades, os fluxos de Cavez (Bateira e Soares, 1992), S. João, Melgaço (Bateira et al., 1998), ou os de Sta. Marinha do Zêzere (Soares et al., 2007) e Rio Frio (Pereira, 2009), salientando-se, para os movimentos mais profundos, os que ocorreram em Covelo do Gerês (Pedrosa et al., 1995) e em Cestães (Bateira et al., 2007).

\subsection{Resistência e condutividade hidráulica}

As características texturais dos materiais de superfície analisados refletem-se na sua resistência, que, de forma indireta e como já referimos, também permite inferir a espessura das formações, a sua compacidade e coesão. 
$\mathrm{Na}$ área situada em torno da cicatriz principal do fluxo de Frades, verificamos que são obtidos valores máximos de resistência a níveis relativamente superficiais. Recorrendo a valores médios, observa-se uma tendência 'normal' de aumento da resistência com a profundidade, embora as discrepâncias ao nível dos segmentos de amostragem sejam evidentes (Figura 5). No segmento A, era já atingido o valor máximo registado pelo penetrómetro $\left(800 \mathrm{~N} / \mathrm{cm}^{2}\right)$ a $25 \mathrm{~cm}$ e a $50 \mathrm{~cm}$ de profundidade, respetivamente, em $43 \%$ e $78.3 \%$ do total dos pontos de amostragem. No segmento intermédio (B), embora
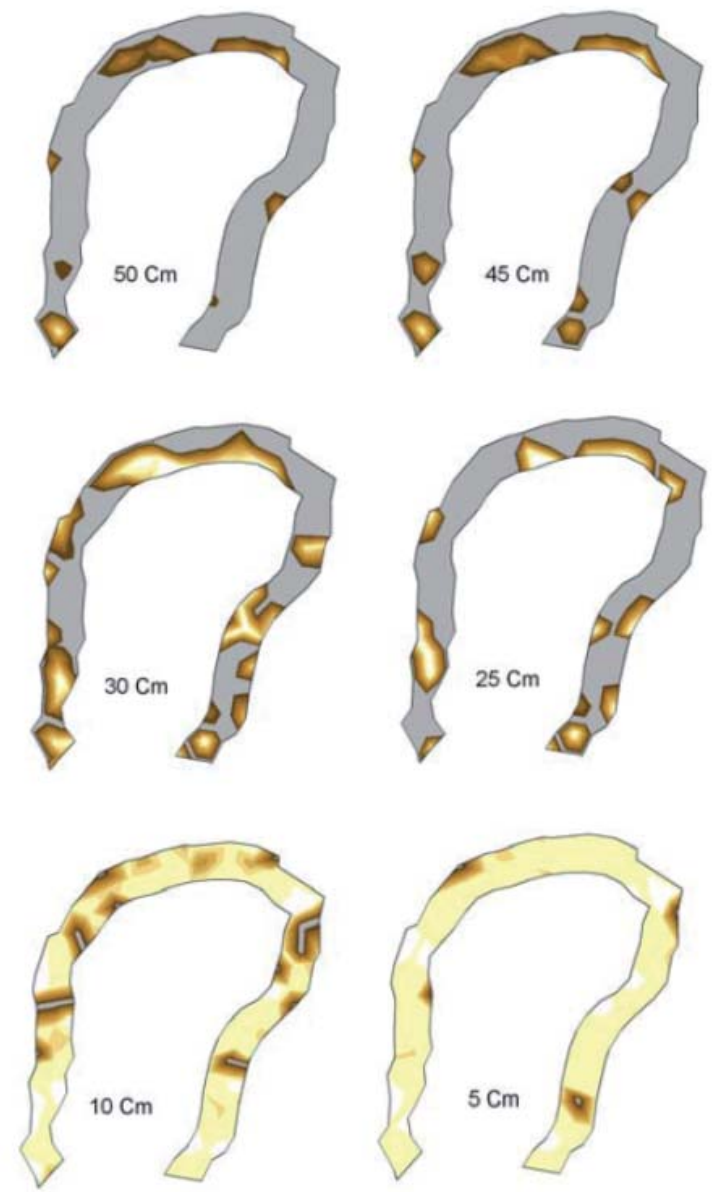

Figura 5 - Resistência dos materiais em torno da cicatriz.

Outro aspeto relevante para o estudo, prende-se com a existência de pontos de amostragem em que a transição entre leituras consecutivas é extremamente rápida. Efetivamente registaram-se situações em que, entre duas ou três medições, eram obtidos valores que mudavam abruptamente de $120-160 \mathrm{~N} / \mathrm{cm}^{2}$ para $800 \mathrm{~N} /$ $\mathrm{cm}^{2}$ (Figura 6,1). Tal verificou-se, por exemplo, na margem direita da cicatriz a $15 \mathrm{~cm}$ de profundidade, se registem maiores irregularidades, esta percentagem aumenta para $59,5 \%$ a $25 \mathrm{~cm}$ e $85,7 \%$ a $50 \mathrm{~cm}$. No mais afastado da cicatriz (C), destaca-se sobretudo o facto de $90.5 \%$ dos pontos de leitura máxima se observarem já a $50 \mathrm{~cm}$ de profundidade (Soares, 2008). Estes dados indiciam a fraca espessura do material sobrejacente ao substrato rochoso ou a presença de formações mais coesas e compactas (i.e. manto de alteração de estrutura conservada), tal como os levantamentos de campo efetuados em vários cortes ao longo do fluxo revelavam.
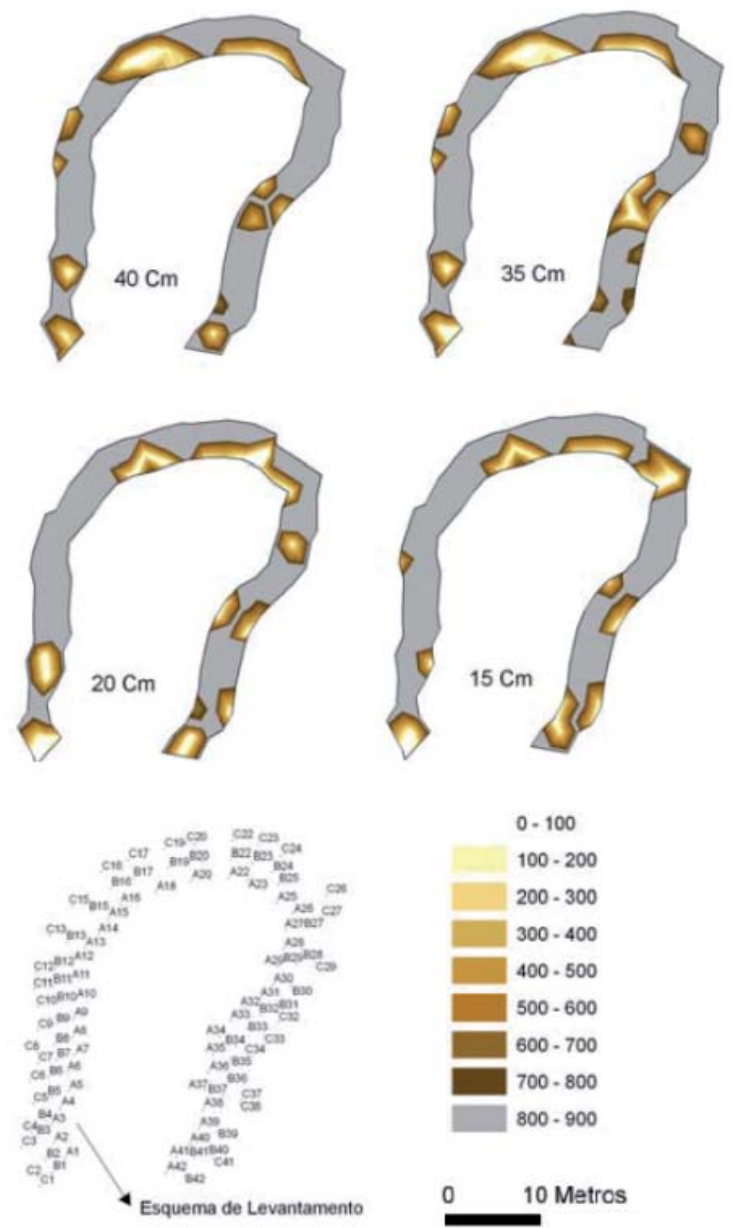

nos pontos que coincidiam com a falha colmatada por material com teores de silte e argila superior a $46 \%$.

Mas o que nos parece mais relevador, são os casos em que por vezes se observa um decréscimo da resistência em profundidade, contrariando a tendência considerada 'normal'. Neste contexto, destacam-se mesmo situações em que o penetrómetro não regista qualquer valor a dada(s) profundidade(s), retomando-se 
posteriormente as leituras, de acordo com a sequência esperada de aumento da resistência (Figura 6, 2). Esta questão parece-nos pertinente, podendo ser explicada pela existência de 'vazios' ou modificações na textura das formações superficiais, onde provavelmente ocorre uma concentração e circulação preferencial dos fluxos de água, definindo uma rede de drenagem subsuperficial.

Esta ideia parece ser reafirmada pelos resultados da condutividade hidráulica, principalmente pelos valores negativos que por vezes foram obtidos para a Matriz do Fluxo Potencial e o Parâmetro Alfa, traduzindo a existência de alterações ou descontinuidades no comportamento da circulação da água em profundidade, associada a variações texturais/estruturais das formações de superfície.
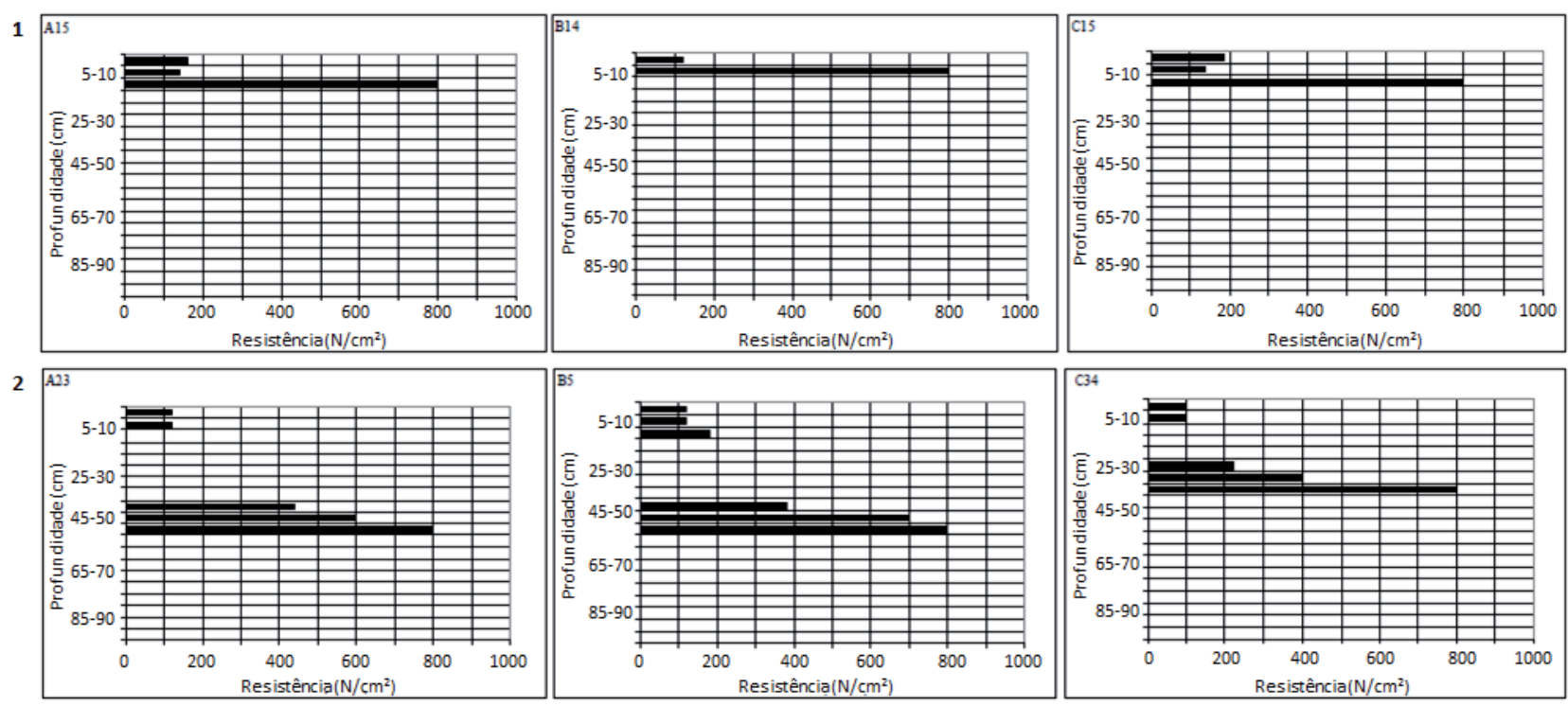

Figura 6 - Resistência à penetração dos materiais. 1. Transição brusca de valores a níveis superficiais; 2. Presença de 'vazios’na sequência de leituras.

\subsection{Refração sísmica aplicada à determinação da espes- sura e drenagem subsuperficial}

A refração sísmica, método geofísico aplicado essencialmente em estudos de engenharia (Moura e Ribeiro, 2009), permite obter informações sobre as características dos maciços rochosos através da análise das diferenças na velocidade de propagação das ondas $\mathrm{P}$, revelando a existência de zonas de descontinuidade, de competência mecânica em profundidade. Neste contexto é aplicada com diversos propósitos, salientando-se, nomeadamente, a determinação da profundidade a que se situa a transição entre diferentes materiais, o estado de alteração e fracturação, a existência de cavidades e a presença de água subterrânea (Moura e Ribeiro, 2009; Santos, 2011). No contexto do presente estudo, os resultados obtidos permitiram criar um 'modelo digital do bedrock' da área afetada, demonstrando a variação da espessura dos materiais atravessados (Figura 7) (Rodrigues, 2013).

Para além da relativa homogeneidade observada nos perfis PS1 a PS3, o que parece importante salientar é o facto das formações superficiais atingirem profundidades superiores a montante do local atravessado pela falha ( $c f$. PS5, Figura 7), podendo associar-se a um efeito de bloqueio da drenagem interna promovida pelo material argiloso que a preenche. Facilitando a concentração/acumulação de água, a meteorização processa-se com maior intensidade neste sector, embora para montante, na proximidade da cicatriz principal, a espessura seja substancialmente inferior. Tal é refletido pelos próprios valores de resistência, que, como vimos, tendem a aumentar do 'interior' para o 'exterior' da cicatriz.

Considerando os dados resultantes da refração sísmica e articulando-a com a informação derivada da resistência e condutividade hidráulica - que, como vimos, indicia a existência de caminhos preferenciais da circulação interna da água associados à variação das características das formações superficiais -, foi construído um modelo topográfico da vertente de Frades, derivando-se posteriormente, através duma análise dire- 
Bateira C. V. M. et al.

cional de fluxos, a rede de drenagem superficial (Figura 8A). A este modelo foi então 'subtraído' o material não consolidado, de forma a obtermos a topografia de "pro-
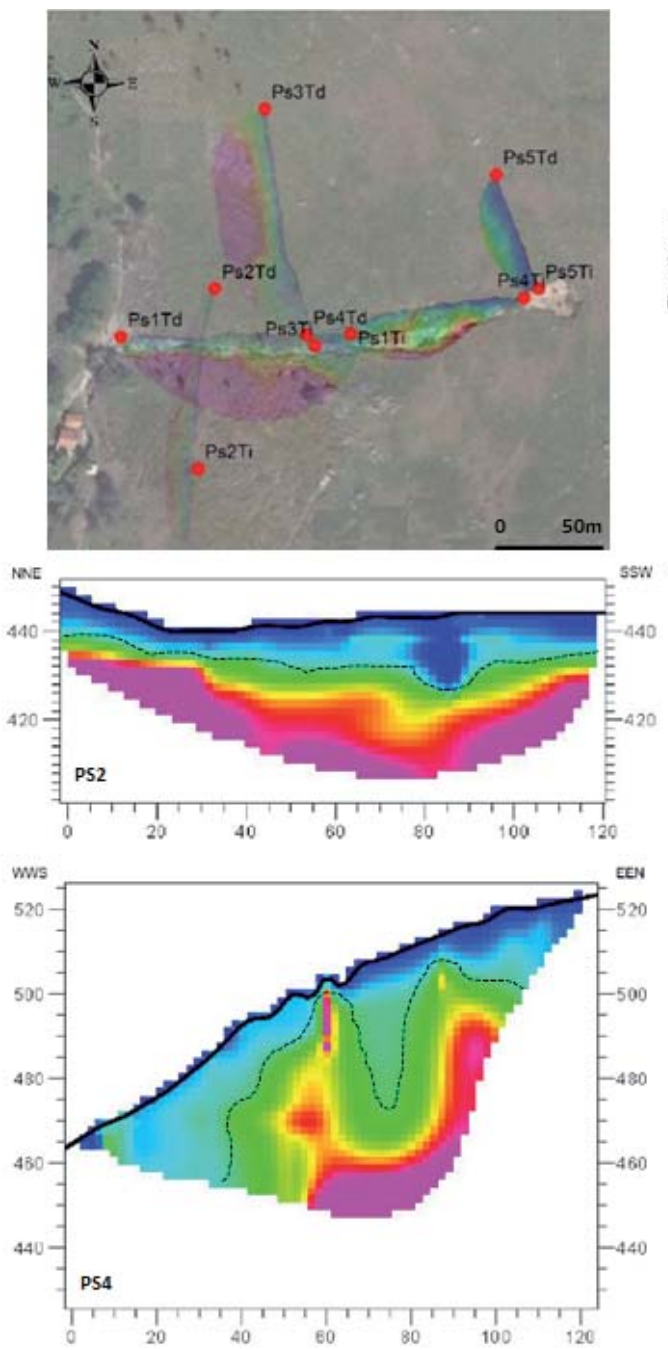

fundidade', que permitiu, pelo mesmo procedimento anterior, obter a configuração da drenagem subsuperficial (Figura 8B).
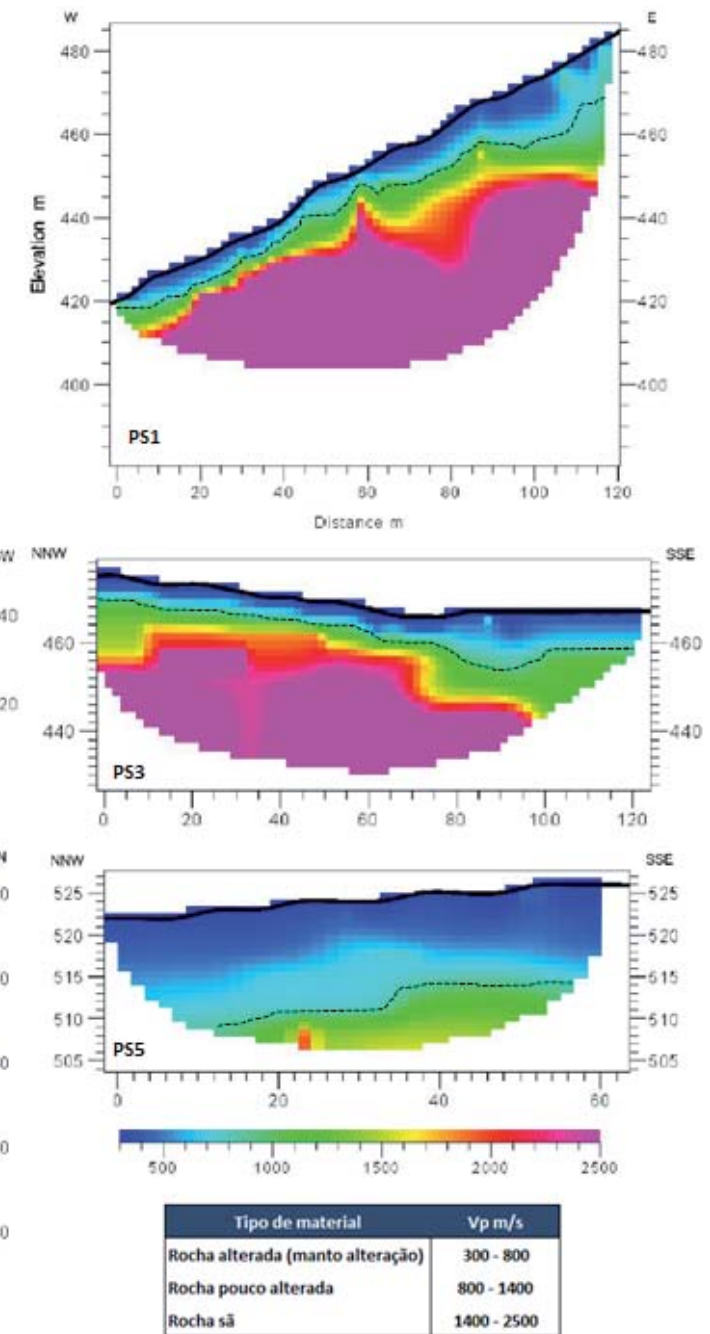

Figura 7 - Velocidade das ondas P nos diferentes perfis. Adaptado de Rodrigues, 2013.

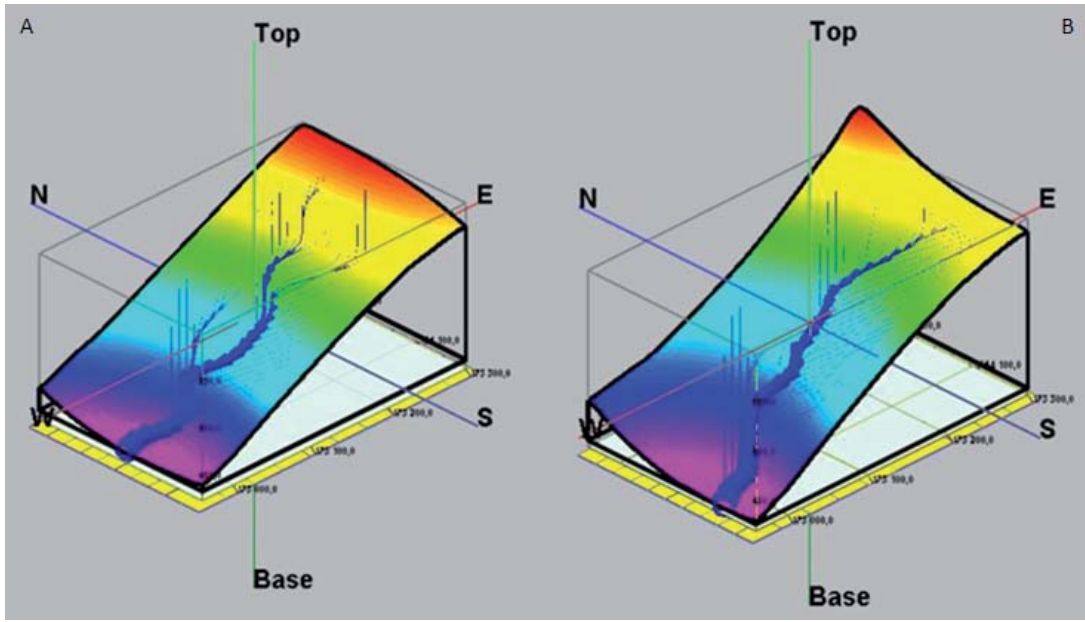

Figura 8 - Caminhos preferenciais da drenagem superficial (A) e subsuperficial (B). 
A nítida relação existente entre o escoamento à superfície e o que se processa interiormente, demonstram que a instabilidade, sempre associada à saturação das formações superficiais, neste caso se associa não à subida do nível freático mas ao efeito de um intenso e concentrado acréscimo de água numa área em que dominam materiais não consolidados pouco espessos. Estes materiais, de textura diferenciada, permitem a infiltração e circulação dos fluídos a profundidades distintas em função do seu grau de coesão e da presença de níveis mais ou menos argilosos (como revelam os dados de resistência e condutividade hidráulica), até ser atingido um limiar que conduz à sua rutura.

\subsection{Modelação do escoamento de acordo com a área de contribuição}

A área de Frades reúne uma série de condicionamentos que justificam a sua perigosidade, mesmo a uma escala de análise regional (Figura 9A). Com efeito, tendo em conta parâmetros como os declives, litologia, rede de fracturação e a variação da precipitação máxima acumulada em 90 dias, os resultados ilustram uma probabilidade muito elevada de ocorrência de movimentos de vertente neste local (Bateira et al., 2007).

Tendo em conta a informação de detalhe recolhida, procedeu-se ao cálculo da área de contribuição utilizando o método multi-direcional de Quinn et al. (1991), de forma a obtermos o padrão espacial do escoamento a partir da análise da área de contribuição a montante. Este método, que pode ser utilizado em estudos de previsão de áreas de instabilidade geomorfológica, distribui o fluxo de forma proporcional entre as células que se situam a jusante - em função do declive local constituindo um dos passos necessários à definição do modelo hidrológico utilizado de forma combinada com o de estabilidade de vertentes no Shalstab (Montgomery e Dietrich, 1994).

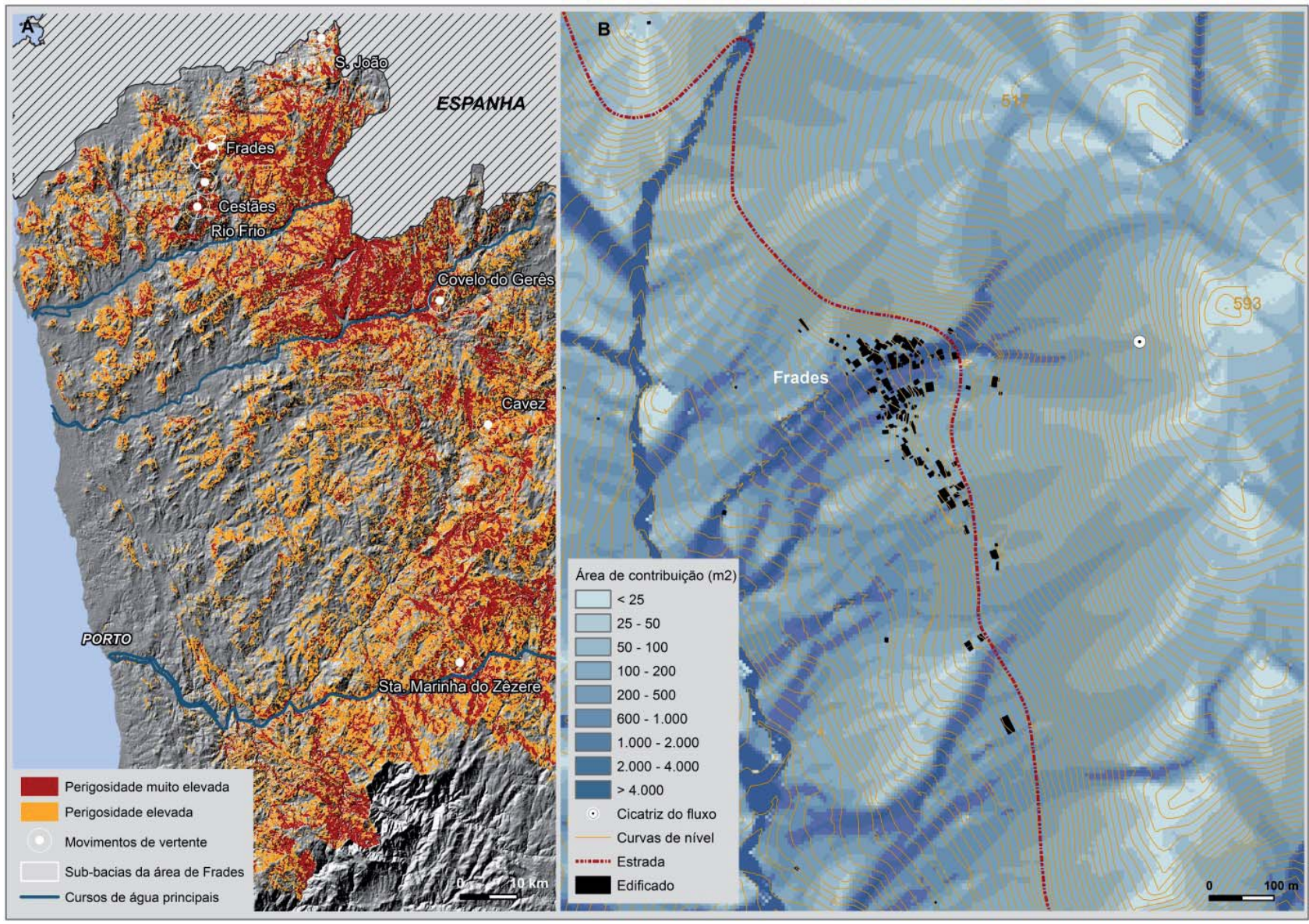

Figura 9 - A. Modelação da perigosidade a movimentos de vertente aplicada ao norte de Portugal (informação de base e modelação otimizada para uma escala de 1:25.0000). B. Área de contribuição associada ao fluxo de Frades (informação de base e modelação otimizada para a escala 1:5.000). 
O resultado obtido (Figura 9B), para além de definir uma rede de drenagem que se aproxima da rede modelada com recurso aos dados registados através da refração sísmica ( $c$. Figura $8 \mathrm{~A}$ ), demonstra uma distribuição coerente com o padrão observado in situ, adaptando-se não só à morfologia do terreno, mas traduzindo os condicionamentos estruturais identificados. As observações monitorizadas in situ pela refração sísmica demonstram a existência de uma estrutura que potencia o escoamento interno feito por caminhos preferenciais, condizente com a ideia de uma forte correlação entre os modelos hidrológicos concebidos a partir dos modelos digitais de elevação.

\section{Conclusão}

Os estudos de suscetibilidade a movimentos de vertente no norte de Portugal, tem permitido demonstrar que as características da precipitação, associada à forma como as formações superficiais respondem à infiltração e circulação interna da água, constituem fatores 'determinantes' no desenvolvimento de ocorrências de tipologia diferenciada. Com efeito, o aumento do teor de água no contexto de uma massa de materiais implica, para além da modificação do seu peso específico, um acréscimo das pressões intersticiais, bem como a diminuição da sua coesão.

No caso de formações de granulometria fina e de fraca espessura, episódios de chuva intensos e concentrados implicam uma saturação rápida dos materiais, que, aumentando a distância entre as partículas promovem a referida diminuição da coesão, levando ao desenvolvimento de movimentos superficiais (Wieczorek, 1996).

$\mathrm{O}$ estudo do fluxo de Frades enquadra-se neste panorama, salientando-se a sua ligação com a progressão vertical da água a níveis subsuperficiais pouco profundos, que colmatando os vazios existentes aumenta a pressão dos poros, promovendo a diminuição da resistência ao corte. Esta diminuição, conduz ao desenvolvimento de planos de rutura no contacto entre uma faixa mais superficial de 'solo' saturado e o material subjacente, numa resposta quase imediata ao intenso e concentrado input de água.

Para além de demonstrar a existência de caminhos preferenciais da circulação interna da água, em associação com condicionamentos ligados às características das formações superficiais, este trabalho revela que a rede de drenagem subsuperficial tem uma ligação evidente com o escoamento que se processa à superfície, embora possa sofrer alterações motivadas por estruturas subjacentes.

\section{Referências Bibliográficas}

ALVES, M.I. Materiais Plio-Quaternários do Alto Minho. Produtos de meteorização e depósitos fluviais na bacia do rio Lima e região de Alvarães. 277p. Tese de Doutoramento, Universidade do Minho, Braga. 1995.

BATEIRA, C.; SOARES, L. O fluxo de detritos de Cavez. Um exemplo de movimento de massa na evolução actual de vertentes. Actas do VI Colóquio Ibérico de Geografia, vol. 2, Publicações da Universidade do Porto, pp.985-998. 1992-1995.

BATEIRA, C.; SOARES, L.; GARCIA, J. O terramoto e S. João (Melgaço) em 1841: um percurso pela geomorfologia histórica. Inforgeo, ${ }^{\circ}$ 12/13, Lisboa, pp.83-98, 1998.

BATEIRA, C.; SOARES, L. Movimentos em massa no norte de Portugal. Factores da sua ocorrência, Territorium, Coimbra, nº, pp.63-77. 1997.

BATEIRA, C. Movimentos de vertente, susceptibilidade geomorfológica e Sistemas de Informação Geográfica. 475p. Dissertação de doutoramento em Geografia Física, Faculdade de Letras, Universidade do Porto. 2001.

BATEIRA, C.; PEREIRA, S.; MARTINS, L.; SANTOS, M. Riscos Extensivos. Plano Regional do Ordenamento do Território do Norte - PROT-Norte, 89p, 2007.

BATEIRA, C. Avaliação da susceptibilidade natural na região norte de Portugal. Análise prospectiva e ordenamento do território. Prospectiva e Planeamento, Vol. 17, pp.15-32. 2010.

BATEIRA, C.; SANTOS, M.; HERMENEGILDO, C.; SOARES, L.; PEREIRA, S.; QUARESMA, I.; SANTOS, P. Distribuição temporal dos desastres naturais de origem hidrogeomorfológica em Portugal continental (1865-2010). Atas/ Proceedings do VI Congresso Nacional de Geomorfologia, Coimbra, pp. 110-114. 2013.

BRAGA, Ma . A. Arenas e depósitos associados na bacia de drenagem do rio Cávado (Portugal). Contribuição para o estudo da arenização. 325p. Dissertação de Doutoramento, Universidade do Minho, Braga. 1998.

BROOKS, S..; CROZIER, M.; PRESTON, N.; ANDERSON, M. Regolith stripping and the control of shallow translational hillslope failure: application of a two-dimensional coupled soil hydrology-slope stability model, Hawke's Bay, New Zealand. 
Geomorphology, 45, pp.165-179. 2002.

COROMINAS, J.; MOYA, J. Reconstructing recent landslide activity in relation to rainfall in the Llobregat River basin, Eastern Pyrenees, Spain. Geomorphology, 30, 1-2, pp. 79-93. 1999.

CROSTA G.; FRATTINI, P. Rainfall thresholds for triggering soil slips and debris flow. In: Mediterranean Storms (Mugnai A, Guzzetti F, Roth G, eds), Proceedings of the 2nd EGS Plinius Conference on Mediterranean Storms. Siena, Italy, pp. 463-487, 2001.

FURTADO, A. Novos dados sobre a presença de gibsite em solos derivados de granitos do NW de Portugal. Garcia da Horta, Série Geologia, Lisboa, Vol. 5, nº1, pp.19-37. 1981-82.

GUIMARÃES, R.; GOMES, R.; JÚNIOR, O.; MARTINS, E.; OLIVEIRA, S.; FERNANDES, N. Análise temporal das áreas susceptíveis a escorregamentos rasos no Parque Nacional da Serra dos Órgãos (RJ) a partir de dados pluviométricos. Revista Brasileira de Geociências, 39(1), pp. 190-198. 2009.

GUZZETTI, F.; PERUCCACCI, S.; ROSSI, M.; STARK, C. Rainfall thresholds for the initiation of landslides in central and southern Europe. Meteorology and Atmospheric Physics, 98, pp.239-267. 2007.

GUZZETTI, F.; PERUCCACCI, S.; ROSSI, M.; STARK, C. The rainfall intensity-duration control of shallow landslides and debris flows: an update. Landslides, 5, pp. 3-17, 2008.

INNES, J. Debris flows. Progress in Physical Geography, vol. 7, no. 4, pp. 469-501. 1983.

JULIÃO, R.; NERY, F.; RIBEIRO, J.; BRANCO, M.; ZÊZERE, J. Guia Metodológico para a Produção de Cartografia Municipal de Risco e para a Criação de Sistemas de Informação Geográfica (SIG) de Base Municipal. ANPC, 93p. 2009.

LAMBE, P. Residual Soils. In: Landslides. Investigation and mitigation. Turner, A. K. e Schuster, R. L. (Eds.), Transportation Research Board, Special Report 247, National Academy Press, Washington D. C., pp. 507-524. 1996.

MALET, J.-P.; REMAÎTRE, A.; MAQUAIRE, O.; ANCEY, C.; LOCAT, J. Flow susceptibility of heterogeneous marly formations: implications for torrent hazard control in the Barcelonnette Basin (Alpes-de- Haute-Provence, France). In: Debris-Flow Hazards Mitigation: Mechanics, Prediction, and Assessment, Rickenmann \& Chen (eds), Millpress, pp.351362. 2003.

MONTGOMERY D.; DIETRICH W. A physically based model for the topographic control on shallow landsliding. Water
Resources Research, 30, pp. 1153-1171. 1994.

MURTHY, V. Geotechnical Engineering: Principles and Practices of Soil Mechanics and Foundation Engineering. CRC Press, 1056 p. 2002.

OLIVEIRA, S.C.; ROCHA, J.; ZÊZERE, J.L.; GARCIA, R.A.C; PIEDADE, A. Avaliação da susceptibilidade a deslizamentos rotacionais através da aplicação de métodos estatísticos. Actas da VI Conferência Nacional de Cartografia e Geodesia. LIDEL, Edições Técnicas, Lda. Lisboa, pp. 530-539. 2010.

OYAGI, N. Landslides in weathered rocks and residual soils in Japan and surrounding areas: a state of the art report. 4th International Symposium on Landslides, Toronto, Vol.3, pp.1-31. 1984.

PRIOR, D.; STEPHENS, N.; DOUGLAS, G. Some examples of mudflow and rockfall activity in North East Ireland. Institute of British Geographers, Special Publication 3, pp. 129-140. 1971.

PEDROSA, A.; BATEIRA, C.; SOARES, L. Covelo do Gerês: Contributo para o estudo dos movimentos de massa no Norte de Portugal. Territorium, Coimbra, nº2, pp. 21-32. 1995.

PEREIRA, S.; BATEIRA, C.; SANTOS, M. Base de dados de movimentos de vertente: um instrumento de apoio ao PROTNorte. Inforgeo, 22-23, pp.24 - 36. 2007.

PEREIRA, S. Perigosidade a movimentos de vertente na região Norte de Portugal. 373p. Tese de Doutoramento em Geografia Física, Faculdade de Letras, Universidade do Porto. 2009.

PEREIRA, S.; ZÊZERE, J.L.; BATEIRA, C. Estabelecimento de limiares de precipitação de base empírica para a ocorrência de fluxos de lama e de detritos no Norte de Portugal. Publicações da Associação Portuguesa de Geomorfólogos, Vol. VI, pp. 155-162. 2010.

PIMENTA, R. Avaliação da Susceptibilidade à Ocorrência de Movimentos de Vertente com Métodos de Base Física. 164p. Dissertação de Mestrado, Universidade de Lisboa. 2011. PULLAMMANAPPALLIL, S. K.; LOUIE, J.N. A generalized simulated-annealing optimization for inversion of first-arrival times. Bulletin of the Seismological Society of America, Vol.84, nº5, pp. 1397-1409. 1994.

QUINN, P.; BEVEN, K.; CHEVALLIER, P.; PLANCHON, O. The prediction of hillslope flow paths for distributed hydrological modelling using digital terrain models. In: Beven, K. and Moore, I. (ed.) Terrain analysis and distributed modelling in hydrology. John Wiley \& Sons, pp. 63-84. 1993. 
RAMOS, V.; GUIMARÃES, R.; REDIVO, A.; CARVALHO JUNIOR, O.; FERNANDES, F.; GOMES, R. Avaliação de Metodologias de Determinação do Cálculo de Áreas de Contribuição. Revista Brasileira de Geomorfologia, Ano 4, no 2, pp. 41-49. 2003.

REYNOLDS, W. Saturated hydraulic conductivity: Field measurement. In M.R. Carter (ed) Soil sampling and methods of analysis. Lewis Publ., Boca Raton, FL. pp. 599-613. 1993.

RODRIGUES, D. (2013) - Sísmica de Refração aplicada ao estudo de fluxos de detritos. Frades, Arcos de Valdevez. 120p. Dissertação de Mestrado, Faculdade de Letras, Universidade do Porto. 2013.

SANGlerat, G. The Penetrometer and Soil Exploration. Elsevier, 464 p. 1972.

SANTOS, P. Cartografia de espessuras de alteração numa zona piloto da margem do Douro através de métodos sísmicos: Implicações para o Ordenamento do Território. Tese de Doutoramento. Universidade de Porto. 2011.

SANTOS, M.; FRAGOSO, M. Mapping extreme rainfall in the Northwest Portugal region: statistical analysis and spatial modelling. Viena, European Geosciences Union, Vol. 12., EGU2010-9031. 2010.

SCHUSTER, R.; WIECZOREK, G. Landslide triggers and types. In: Landslides. Rybbár, Stemberk \& Wagner (Eds.), pp. 59-75. 2002.

SHARMA, R.; MEHTA, B.; JAMWAL, C. Cut slope stability evaluation of NH-21 along Nalayan-Gambhrola section, Bilaspur district, Himachal Pradesh, India. Natural Hazards, Vol. 66 Issue 2, pp. 249-270. 2013.

SILVÉRIO, M. Erosão hídrica de solos na Serra da Aboboreira. 220p. Dissertação de Mestrado, Faculdade de Letras, Universidade do Porto. 2000.

SOARES, L. As serras de Campelos Maragotos. Contributo para um estudo de morfologia granítica. 149 p. Dissertação de Mestrado, Universidade do Coimbra. 1992.

SOARES, L.; BATEIRA, C.; GOMES, A. Fluxo de Sta Marinha do Zêzere (NW de Portugal): ensaio metodológico. Revista da Faculdade de Letras - Geografia, II série, vol. I, pp 87-124. 2007.

SOARES, L. A importância das formações superficiais no âmbito dos processos de erosão hídrica e movimentos de vertente no NW de Portugal. 850p. Dissertação de doutoramento em Geografia Física, Faculdade de Letras, Universidade do Porto. 2008.
SOARES, L.; BATEIRA, C.; PEREIRA, S.; SEIXAS, A.; HERMENEGILDO, C. Processos de escoamento em terraços agrícolas no vale do Douro: comportamento hídrico em diferentes tipos de formações superficiais e secções de vertente. XII Colóquio Ibérico de Geografia, Porto. 2010. Disponível em http://web.letras.up.pt/xiicig/resumos/144.pdf.

SOARES, L.; BATEIRA, C. As formações superficiais como factor condicionante dos movimentos de vertente no NW de Portugal. Actas/Proceedings do V Congresso Nacional de Geomorfologia, Porto, pp. 481-485. 2010.

SOARES, L.; BATEIRA, C. Movimentos de massa em vertentes no Norte de Portugal. Retrospectiva e actualização. In: Riscos Naturais, Antrópicos e Mistos. Homenagem ao Professor Doutor Fernando Rebelo. Departamento de Geografia da Faculdade de Letras da Universidade de Coimbra, pp.367-383. 2013.

TEIXEIRA, M. Avaliação da Suscetibilidade à Ocorrência de Deslizamentos Translacionais Superficiais. Utilização de Modelos Matemáticos de Base Física na Bacia de Tibo, Arcos de Valdevez. 125p. Dissertação de Mestrado, Faculdade de Letras da Universidade do Porto. 2012.

TEIXEIRA, M.; BATEIRA, C.; MARQUES, F.; SOARES, L. Suscetibilidade à ocorrência de deslizamentos translacionais superficiais com recurso a modelos matemáticos de base física (Serra da Peneda). Atas/Proceedings do VI Congresso Nacional de Geomorfologia, Coimbra, pp. 119-123. 2013.

TEIXEIRA, M., BATEIRA, C., MARQUES, F., VIEIRA, B. Physically based shallow translational landslide susceptibility analysis in Tibo catchment, NW of Portugal. Landslides, 2014, em impressão (DOI 10.1007/s10346-014-0494-9).

VASCONCELOS, M. () - Cartografia de Susceptibilidade à Ocorrência de Movimentos de Vertente em Contexto Urbano: o Concelho de Lisboa. 232p. Dissertação de Mestrado, Universidade de Lisboa. 2011.

WIECZOREK, G. Landslide Triggering Mechanisms. In Landslides: Investigation and Mitigation. Special Report 247, A. K. Turner and R.L. Schuster Ed., Washington, National Academy Press, pp. 76-90. 1996.

YALCIN, A. The effects of clay on landslides: A case study. Applied Clay Science, 38, pp. 77-85. 2007.

ZÊZERE, J.L. A avaliação da perigosidade geomorfológica. Aplicação do método do valor informativo na área-amostra de Calhandriz. In: Homenagem (in honorum) Professor Gaspar Soares de Carvalho. Moreira, M.E.; Moura, A.C.; Granja, M.H.; Noronha, F. (eds.). Braga, p. 347-361. 2001. 
Movimentos de Vertente no Norte de Portugal: Importância do Comportamento Hidrológico das Formações

ZÊZERE, J.L.; RODRIGUES, M.L. Rainfall Thresholds for Landsliding in Lisbon Area (Portugal). In: Rybar, Stemberk \& Wagner (Eds.), Landslides, A.A. Balkema, Lisse, p.333-338. 2002.

ZÊZERE, J.L.; REIS, E.; GARCIA, R.; OLIVEIRA, S.; RODRIGUES, M.L.; VIEIRA, G.; FERREIRA, A.B. Integration of spatial and temporal data for the definition of different landslide hazard scenarios in the area north of Lisbon (Portugal). Natural Hazards and Earth System Sciences, vol. 4, pp. 133146. 2004.

ZÊZERE, J. L. TRIGO, R.; TRIGO, I. Shallow and deep landslides induced by rainfall in the Lisbon region (Portugal): assessment of relationships with the North Atlantic Oscillation.
Natural Hazards and Earth System Sciences, 5, pp. 331344.* 2005.

ZÊZERE, J.L. Riscos e Ordenamento do Território. Inforgeo, Associação Portuguesa de Geógrafos, 20/21, pp.59-63. 2007.

ZÊZERE, J.L.; RAMOS-PEREIRA, A.; MORGADO, P. Perigos Naturais em Portugal e Ordenamento do Território. E depois do PNPOT? Geophilia - O sentir e os sentidos da Geografia, C.E.G.,Lisboa, p.529-542. 2007.

ZÊZERE, J.L.; TRIGO, R.M.; FRAGOSO, M.; OLIVEIRA, S.C.; GARCIA, R. Rainfall-Triggered Landslides Occurred in the Lisbon Region in 2006: Validation of Regional Rainfall Thresholds and Relationships with the North Atlantic Oscillation. Natural Hazards and Earth System Sciences, 8, pp. 483-499. 2008 . 